Research Article

\title{
Diarylalkanoids as Potent Tyrosinase Inhibitors from the Stems of Semecarpus caudata
}

\author{
Phu H. Dang $\mathbb{D}^{1,2}$ Tho H. Le $\left.{ }^{1}\right)^{1,2}$ Truong N. V. Do ${ }^{10},^{1,2}$ Hai X. Nguyen $\mathbb{D}^{1,2}$ \\ Mai T. T. Nguyen $\mathbb{D}^{1,2,3}$ and Nhan T. Nguyen $\mathbb{D}^{1,2,3}$ \\ ${ }^{1}$ Faculty of Chemistry, University of Science, 227 Nguyen Van Cu Street, Ward 4, District 5, Ho Chi Minh City, Vietnam \\ ${ }^{2}$ Vietnam National University, Quarter 6, Linh Trung Ward, Thu Duc District, Ho Chi Minh City, Vietnam \\ ${ }^{3}$ Cancer Research Laboratory, University of Science, 227 Nguyen Van Cu Street, District 5, Ho Chi Minh City, Vietnam
}

Correspondence should be addressed to Nhan T. Nguyen; ntnhan@hcmus.edu.vn

Received 2 October 2020; Revised 5 November 2020; Accepted 16 December 2020; Published 4 January 2021

Academic Editor: Siba shanak

Copyright (c) $2021 \mathrm{Phu} \mathrm{H.} \mathrm{Dang} \mathrm{et} \mathrm{al.} \mathrm{This} \mathrm{is} \mathrm{an} \mathrm{open} \mathrm{access} \mathrm{article} \mathrm{distributed} \mathrm{under} \mathrm{the} \mathrm{Creative} \mathrm{Commons} \mathrm{Attribution} \mathrm{License,}$ which permits unrestricted use, distribution, and reproduction in any medium, provided the original work is properly cited.

From a $\mathrm{CHCl}_{3}$-soluble extract of the stems of Semecarpus caudata (Anacardiaceae), two new diarylalkanoids, semedienone (1) and semetrienone (2), were isolated. Their structures were elucidated based on NMR spectroscopic data interpretation. These compounds possess strong tyrosinase inhibitory activity with the $\mathrm{IC}_{50}$ values of 0.033 and $0.11 \mu \mathrm{M}$, respectively. Docking studies of $\mathbf{1}$ and $\mathbf{2}$ with $o x y$-tyrosinase were carried out to analyze their interactions. Accordingly, semedienone (1) showed good interactions with the peroxide group and amino acid residues. The biosynthesis of the isolated diarylalkanoids was proposed.

\section{Introduction}

Melanin is a pigment that is essential for protecting human skin against UV radiation. However, the abnormal accumulation of melanin induced skin pigmentation disorders. Melanogenesis is a complex process to produce melanin under control of tyrosinase. Tyrosinase (EC 1.14.18.1) is a binuclear copper-containing monooxygenase, which catalyzes the oxidation of phenol to the corresponding $o$-quinone $[1,2]$. Tyrosinase is the main factor causing some dermatological diseases including freckles, age spots, and melasma. Hydroquinone, arbutin, kojic acid, azelaic acid, L-ascorbic acid, ellagic acid, and tranexamic acid are commercial tyrosinase inhibitors, which have been used as skin-whitening agents, but these compounds have certain drawbacks [3]. Thus, the finding of new efficient and safe antityrosinase agents is necessary for anti-hyperpigmentation drug development.

A previous study on the chemical constituents of Semecarpus caudata (Anacardiaceae), collected at Dong Nai Province in Vietnam, led to the isolation of six flavonoid derivatives and the evaluation of their tyrosinase inhibitory activity [4]. Our continued phytochemical study on the stems of $S$. caudata was carried out, leading to the isolation of seven compounds (1-7) including two new diarylalkanoids named semedienone (1) and semetrienone (2). These compounds were found to possess tyrosinase inhibitory activity. Semedienone (1) showed a strong effect with an $\mathrm{IC}_{50}$ value of $0.033 \mu \mathrm{M}$, which makes it 1300 times more potent than that of kojic acid $\left(\mathrm{IC}_{50}, 44.6 \mu \mathrm{M}\right)$. In addition, molecular docking studies of $\mathbf{1}$ and $\mathbf{2}$ with the $o x y$-form of the copper-bound Streptomyces castaneoglobisporus tyrosinase were performed.

\section{Materials and Methods}

2.1. General Experimental Procedures. Optical values were measured on a Shimadzu UV-1800 spectrophotometer (Shimadzu Pte., Ltd., Singapore). IR spectra were measured with a Shimadzu IR-408 infrared spectrometer (Shimadzu Pte., Ltd., Singapore). NMR spectra were acquired on a Bruker Avance III 500 spectrometer (Bruker BioSpin AG, Bangkok, Thailand). Chemical shifts are expressed as $\delta$ values. HRESIMS data were acquired on Bruker micrOTOFQII mass spectrometer (Bruker Singapore Pte., Ltd., Singapore). Column chromatography was carried out using 
silica gel 60, 0.06-0.2 mm (Scharlau, Barcelona, Spain) and LiChroprep RP-18, 40-63 $\mu \mathrm{m}$ (Merck KGaA, Darmstadt, Germany). Kieselgel $60 \mathrm{~F}_{254}$ or RP-18 $\mathrm{F}_{254}$ plates for TLC were purchased from Merck (Merck KGaA, Darmstadt, Germany). Tyrosinase (EC 1.14.18.1) from mushroom $\left(3933 \mathrm{U} \cdot \mathrm{mL}^{-1}\right.$ ) and L-dihydroxyphenylalanine (L-DOPA) were obtained from Sigma-Aldrich (Sigma-Aldrich Pte., Ltd., Singapore). Other chemicals were of the highest grade available.

2.2. Plant Material. The stems of Semecarpus caudata were collected in the Ma Da Forest, Dong Nai Culture and Nature Reserve, Dong Nai Province, Vietnam, in April 2014. The plant was identified by Assoc. Prof. Dr. Hop Tran, Institute of Tropical Biology, Ho Chi Minh City, Vietnam. A voucher sample (MCE0002) has been deposited at the Division of Medicinal Chemistry, Faculty of Chemistry, University of Science, Ho Chi Minh City, Vietnam.

2.3. Extraction and Isolation. The dried powdered stems of S. caudata $(7.0 \mathrm{~kg})$ were exhaustively extracted in a Soxhlet extractor with $\mathrm{MeOH}(20 \mathrm{~L}, 3 \mathrm{~h} \times 3)$ to yield $\mathrm{MeOH}$-soluble extract $(700 \mathrm{~g})$. This extract was suspended in $\mathrm{H}_{2} \mathrm{O}(5 \mathrm{~L})$ and successively partitioned with $n$-hexane $(2 \mathrm{~L})$ and $\mathrm{CHCl}_{3}(3 \mathrm{~L})$ to give $n$-hexane $(37 \mathrm{~g})$ - and $\mathrm{CHCl}_{3}(500 \mathrm{~g})$-soluble fractions. The $\mathrm{CHCl}_{3}$-soluble fraction was chromatographed by silica gel column chromatography $(15 \times 150 \mathrm{~cm})$ and eluted with EtOAc$n$-hexane $(0: 100 \longrightarrow 100: 0)$ and $\mathrm{MeOH}-\mathrm{CHCl}_{3}(0: 100 \longrightarrow$ $20: 80$ ) to afford 12 fractions (Fr.1-Fr.12). Fraction Fr.3 (4.5 g) was subjected to further silica gel column chromatography and was eluted with EtOAc- $n$-hexane $(0-100 \%)$ to yield 4 subfractions (Fr.3.1-Fr.3.4). Subfractions Fr.3.2 (1.1 g) and Fr.3.3 $(540 \mathrm{mg}$ ) were chromatographed over a silica gel column with EtOAc- $n$-hexane $(0-100 \%)$ and purified by preparative TLC

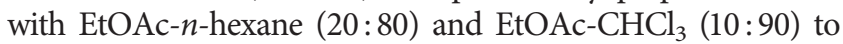
afford $5(5.0 \mathrm{mg})$ and $7(6.0 \mathrm{mg})$, respectively. Fraction Fr.5 $(5.2 \mathrm{~g})$ was separated by silica gel column chromatography with EtOAc- $n$-hexane $(0-100 \%)$ and $\mathrm{MeOH}-\mathrm{CHCl}_{3}(0-20 \%)$ to yield 5 subfractions (Fr.5.1-Fr.5.5). Subfraction Fr.5.3 (850 mg) was subjected to further silica gel column chromatography, eluted with $\mathrm{Me}_{2} \mathrm{CO}-\mathrm{CHCl}_{3}(0-80 \%)$ to give 4 (5.0 mg). Fraction Fr.6 $(0.9 \mathrm{~g})$ was separated by normal-phase chromatography with EtOAc- $n$-hexane $(0: 100 \longrightarrow 80: 20)$ and $\mathrm{MeOH}-\mathrm{CHCl}_{3}$ $(0: 100 \longrightarrow 5: 95)$ and reversed phase chromatography with $\mathrm{H}_{2} \mathrm{O}-\mathrm{MeOH}(0-100 \%)$ and then purified by preparative TLC with AcOH-EtOAc-PhMe $(4: 16: 80)$ to obtain $3(4.0 \mathrm{mg})$ and 6 $(4.0 \mathrm{mg})$. Fraction Fr.8 $(4.5 \mathrm{~g})$ was loaded onto a silica gel column and eluted with $\mathrm{CHCl}_{3}-\mathrm{Me}_{2} \mathrm{CO}(0-80 \%)$ and $\mathrm{CHCl}_{3^{-}}$ $\mathrm{MeOH}(0-20 \%)$ to yield 5 subfractions (Fr.8.1-Fr.8.5). Subfraction Fr.8.2 $(630 \mathrm{mg})$ was further purified using a silica gel column with EtOAc- $\mathrm{CHCl}_{3}(0-80 \%)$ and preparative TLC with

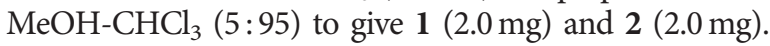

2.3.1. Semedienone (1). Yellow, amorphous solid; IR $v_{\max }$ $\left(\mathrm{CHCl}_{3}\right): 3455,1620,1485,1250,1091 \mathrm{~cm}^{-1} ;{ }^{1} \mathrm{H}$ and ${ }^{13} \mathrm{C}$ NMR $\left(500 \mathrm{MHz}\right.$, acetone- $d_{6}$, see Table 1 ); HRESIMS $\mathrm{m} / z$ $321.0752[\mathrm{M}+\mathrm{Na}]^{+}$(calcd. for $\mathrm{C}_{17} \mathrm{H}_{14} \mathrm{O}_{5} \mathrm{Na}, 321.0739$ ).
2.3.2. Semetrienone (2). Yellow, amorphous solid; IR $v_{\max }$ $\left(\mathrm{CHCl}_{3}\right): 3305,1650,1430,1245,1085 \mathrm{~cm}^{-1} ;{ }^{1} \mathrm{H}$ and ${ }^{13} \mathrm{C}$ NMR $\left(500 \mathrm{MHz}\right.$, acetone- $d_{6}$, see Table 1 ); HRESIMS $\mathrm{m} / z$ $347.0902[\mathrm{M}+\mathrm{Na}]^{+}$(calcd. for $\left.\mathrm{C}_{19} \mathrm{H}_{16} \mathrm{O}_{5} \mathrm{Na}, 347.0895\right)$.

2.4. Synthesis of $2,4,2^{\prime}, 4^{\prime}$-Tetrahydroxychalcone (8). 2,4-Dihydroxybenzaldehyde (276.3 mg, $2.0 \mathrm{mmol}$ ) and 2',4'dihydroxyacetophenone $(152.1 \mathrm{mg}, 1.0 \mathrm{mmol})$ were dissolved in $1 \mathrm{~mL} \cdot \mathrm{H}_{2} \mathrm{O}$, and then $1 \mathrm{~mL} \mathrm{KOH} 14 \mathrm{M}$ was added. The resulting mixture was kept in the ultrasonic water bath at $80^{\circ} \mathrm{C}$ for $8 \mathrm{~h}$. This reaction was monitored by TLC using $\mathrm{MeOH}-\mathrm{CHCl}_{3}(1: 9)$ mixture. After completion, the reaction mixture was quenched by acidification with $\mathrm{HCl} 3 \mathrm{M}$ to $\mathrm{pH}$ $\sim 5$ and cooled to $0^{\circ} \mathrm{C}$ to precipitate crude product, which was recrystallized with $\mathrm{MeOH}-\mathrm{H}_{2} \mathrm{O}(1: 3)$ mixture to afford pure chalcone. It was identified as $2,4,2^{\prime}, 4^{\prime}$-tetrahydroxychalcone (8), by comparison with authentic sample.

2.5. Tyrosinase Inhibitory Assay. All pure compounds were dissolved in DMSO and tested at concentrations ranging from 0.01 to $100 \mu \mathrm{M}$. Assay mixtures in $0.1 \mathrm{M}$ phosphate buffer $\mathrm{pH}$ 6.8 were prepared immediately before use, consisting of $100 \mu \mathrm{L}$ of tyrosinase solution $(15 \mathrm{U} / \mathrm{mL})$ and $1900 \mu \mathrm{L}$ of test solution. These mixtures were preincubated at room temperature for $30 \mathrm{~min}$, followed by addition of $1000 \mu \mathrm{L}$ of L-DOPA $1.5 \mathrm{mM}$ in pH 6.8 phosphate buffer and incubated at room temperature for $7 \mathrm{~min}$. The absorbances $(A)$ at $475 \mathrm{~nm}$ were acquired on Shimadzu UV-1800 spectrophotometer. The inhibitory percentage (I\%) was calculated according to the formula: $I$ $\%=\left(\left(A_{\text {control }}-A_{\text {sample }}\right) / A_{\text {control }}\right) \times 100 \%$. Data were represented as means \pm standard error $(n=3)$. The $\mathrm{IC}_{50}$ values were determined by using GraphPad Prism software with multivariate nonlinear regression and $R^{2}>0.9$. Kojic acid was used as positive control.

2.6. Molecular Docking. Docking studies of $\mathbf{1}, \mathbf{2}, \mathbf{8}$, and the positive reference (kojic acid) were performed with Molecular Operating Environment 2016 (MOE 2016.0802) suite. The structures of these compounds were constructed by using the Builder module. Subsequently, all compounds were minimized up to 0.0001 gradients using the Amber12: EHT force field. The crystal structure of the oxy-tyrosinase was taken from the Protein Data Bank (PDB code 1WX2). The caddie protein (ORF378) and water molecules were removed. The enzyme structure was prepared using the QuickPrep module. The binding site was determined based on the PLB (Propensity for Ligand Binding) score in the Site Finder module. The molecular docking was performed by Dock module, using Triangle Matcher placement, Induced Fit refinement, London dG, and GBVI/WSA dG scoring methods. Five top poses showed up based on the negative binding free energy value ( $S$ value). The best pose was selected to analyze the receptor-ligand interactions by using BIOVIA Discovery Studio Visualizer 2016.

\section{Results and Discussion}

3.1. Extraction and Isolation. The dried powdered stems of S. caudata were exhaustively extracted in a Soxhlet extractor 
Table 1: ${ }^{1} \mathrm{H}(500 \mathrm{MHz})$ and ${ }^{13} \mathrm{C}(125 \mathrm{MHz}) \mathrm{NMR}$ data (acetone- $\left.d_{6}\right)$ for compounds 1 and 2.

\begin{tabular}{|c|c|c|c|c|}
\hline \multirow{2}{*}{ Position } & \multicolumn{2}{|c|}{1} & \multicolumn{2}{|c|}{2} \\
\hline & $\delta_{\mathrm{C}}$, type C & $\delta_{\mathrm{H}}(J, \mathrm{~Hz})$ & $\delta_{\mathrm{C}}$, type $\mathrm{C}$ & $\delta_{\mathrm{H}}(J, \mathrm{~Hz})$ \\
\hline $1^{\prime}$ & $114.5, \mathrm{C}$ & & $114.9, \mathrm{C}$ & \\
\hline $2^{\prime}$ & 167.6, C & & $167.4, \mathrm{C}$ & \\
\hline $3^{\prime}$ & $103.8, \mathrm{CH}$ & $6.35, \mathrm{~d}(2.4)$ & $103.8, \mathrm{CH}$ & $6.35, \mathrm{~d}(2.4)$ \\
\hline $4^{\prime}$ & $165.5, \mathrm{C}$ & & $165.9, \mathrm{C}$ & \\
\hline $5^{\prime}$ & $108.7, \mathrm{CH}$ & 6.45, dd $(8.9,2.4)$ & $108.8, \mathrm{CH}$ & 6.45, dd $(8.9,2.4)$ \\
\hline $6^{\prime}$ & $132.9, \mathrm{CH}$ & $7.94, \mathrm{~d}(8.9)$ & 132.6, CH & $7.92, \mathrm{~d}(8.9)$ \\
\hline $\mathrm{C}=\mathrm{O}$ & 192.8, C & & 192.6, C & \\
\hline$\alpha$ & $122.1, \mathrm{CH}$ & $7.27, \mathrm{~d}(14.5)$ & $122.8, \mathrm{CH}$ & $7.26, \mathrm{~d}(14.5)$ \\
\hline$\beta$ & $147.3, \mathrm{CH}$ & 7.68 , dd $(14.5,11.3)$ & $145.8, \mathrm{CH}$ & 7.61, dd $(14.5,11.5)$ \\
\hline$\gamma$ & 125.0, CH & 7.17 , dd $(15.6,11.3)$ & $129.4, \mathrm{CH}$ & 6.62 , dd $(13.7,11.5)$ \\
\hline$\delta$ & $139.5, \mathrm{CH}$ & $7.35, \mathrm{~d}(15.6)$ & $145.8, \mathrm{CH}$ & $7.00, \mathrm{~m}$ \\
\hline$\varepsilon$ & & & 126.1, CH & $7.00, \mathrm{~m}$ \\
\hline$\zeta$ & & & $134.3, \mathrm{CH}$ & $7.13, \mathrm{~d}(14.6)$ \\
\hline 1 & $116.5, \mathrm{C}$ & & 116.6, C & \\
\hline 2 & $158.5, \mathrm{C}$ & & $157.8, \mathrm{C}$ & \\
\hline 3 & 103.7, CH & $6.47, \mathrm{~d}(2.4)$ & 103.7, CH & $6.45, \mathrm{~d}(2.4)$ \\
\hline 4 & 161.0, C & & 161.0, C & \\
\hline 5 & $108.9, \mathrm{CH}$ & 6.42, dd $(8.5,2.4)$ & $108.8, \mathrm{CH}$ & 6.39, dd $(8.5,2.4)$ \\
\hline 6 & $130.2, \mathrm{CH}$ & $7.43, \mathrm{~d}(8.5)$ & 129.3, CH & $7.39, \mathrm{~d}(8.5)$ \\
\hline $\mathrm{OH}-2^{\prime}$ & & $13.68, \mathrm{~s}$ & & $13.64, \mathrm{~s}$ \\
\hline
\end{tabular}

with $\mathrm{MeOH}$ to yield $\mathrm{MeOH}$-soluble extract $(700 \mathrm{~g})$. This extract was successively partitioned to give the $n$-hexane (37 g) - and $\mathrm{CHCl}_{3}(500 \mathrm{~g})$-soluble fractions. The $\mathrm{CHCl}_{3^{-}}$ soluble extract of stems of $S$. caudata was repeatedly chromatographed using silica gel CC and preparative TLC to obtain seven compounds including two new diarylalkanoids named semedienone (1) and semetrienone (2). The known compounds were identified as 2,6-dimethoxybenzoquinone (3) [5], p-coumaric acid (4) [6], methyl $p$-coumarate (5) [7], trans-4-(3,4-dihydroxyphenyl)but-3-en-2-one (6) [8], and ferulic acid (7) [9] (Figure 1).

3.2. Structural Elucidation of Two New Isolated Compounds from $S$. caudata. Compound $\mathbf{1}$ showed a molecular formula to be $\mathrm{C}_{17} \mathrm{H}_{14} \mathrm{O}_{5}$ based on the HRESIMS ion at $m / z 321.0752$ $[\mathrm{M}+\mathrm{Na}]^{+}$(calcd. for $\left.\mathrm{C}_{17} \mathrm{H}_{14} \mathrm{O}_{5} \mathrm{Na}, 321.0739\right)$. The IR spectrum exhibited the presence of hydroxy $\left(3455 \mathrm{~cm}^{-1}\right)$ and carbonyl $\left(1620 \mathrm{~cm}^{-1}\right)$ functionalities. The ${ }^{1} \mathrm{H}$ NMR spectrum showed signals for two 1,2,4-trisubstituted aromatic rings $\left(\delta_{\mathrm{H}} 7.94\left(\mathrm{~d}, J=8.9 \mathrm{~Hz}, \mathrm{H}-6^{\prime}\right), 6.45\left(\mathrm{dd}, J=8.9,2.4 \mathrm{~Hz}, \mathrm{H}-5^{\prime}\right)\right.$, $6.35\left(\mathrm{~d}, J=2.4 \mathrm{~Hz}, \mathrm{H}-3^{\prime}\right), 7.43$ (d, $\left.J=8.5 \mathrm{~Hz}, \mathrm{H}-6\right), 6.47$ (d, $J=2.4 \mathrm{~Hz}, \mathrm{H}-3)$, and $6.42(\mathrm{dd}, J=8.5,2.4 \mathrm{~Hz}, \mathrm{H}-5)$ ), four olefinic protons $\left(\delta_{\mathrm{H}} 7.27(\mathrm{~d}, J=14.5 \mathrm{~Hz}, \mathrm{H}-\alpha), 7.68(\mathrm{dd}\right.$, $J=14.5,11.3 \mathrm{~Hz}, \mathrm{H}-\beta), 7.17$ (dd, $J=15.6,11.3 \mathrm{~Hz}, \mathrm{H}-\gamma)$, and $7.35(\mathrm{~d}, J=15.6 \mathrm{~Hz}, \mathrm{H}-\delta))$, and a distinctive signal of a hydrogen-bonded hydroxy group $\left(\delta_{\mathrm{H}} 13.68\right)$. The ${ }^{13} \mathrm{C} \mathrm{NMR}$ data (Table 1) exhibited resonances for a keto-carbonyl $\left(\delta_{\mathrm{C}}\right.$ $192.8)$, twelve aromatic carbons $\left(\delta_{\mathrm{C}} 103.7-167.6\right)$, and four olefinic carbons $\left(\delta_{\mathrm{C}} 122.1(\mathrm{C}-\alpha), 147.3(\mathrm{C}-\beta), 125.0(\mathrm{C}-\gamma)\right.$, and $139.5(\mathrm{C}-\delta))$. These were characteristic of those reported for $(2 E, 4 E)-1,5$-diarylpenta-2,4-dien-1-one [10,11]. The $\mathrm{HMBC}$ correlations (Figure 2) from OH-2' to C- $1^{\prime}$ and $\mathrm{C}-3^{\prime}$, from $\mathrm{H}-3^{\prime}$ to $\mathrm{C}-1^{\prime}$ and $\mathrm{C}-4^{\prime}$, from $\mathrm{H}-5^{\prime}$ to $\mathrm{C}-1^{\prime}$, from $\mathrm{H}-6^{\prime}$ to C- $2^{\prime}$ and C- $4^{\prime}$, from $\mathrm{H}-3$ to C-1, C-2, and C-4, from $\mathrm{H}-5$ to
C-1, and from H-6 to C-2 and C-4 indicated that four hydroxy groups were located at C-2 $2^{\prime}, \mathrm{C}-4^{\prime}, \mathrm{C}-2$, and C-4. Moreover, the HMBC correlations from $\mathrm{H}-6^{\prime}, \mathrm{H}-\alpha$, and $\mathrm{H}-\beta$ to $\mathrm{C}=\mathrm{O}$, from $\mathrm{H}-\alpha$ to $\mathrm{C}-\gamma$, from $\mathrm{H}-\beta$ to $\mathrm{C}-\delta$, from $\mathrm{H}-\gamma$ to $\mathrm{C}-\alpha$, from $\mathrm{H}-\gamma$ to $\mathrm{C}-\beta$ and $\mathrm{C}-1$, and from $\mathrm{H}-\delta$ to $\mathrm{C}-\beta$ and $\mathrm{C}-6$ suggested the presence of the $\alpha, \beta, \gamma, \delta$-unsaturated carbonyl moiety in 1. The NOESY correlations between $\mathrm{H}-5^{\prime}$ and H- $6^{\prime}, \mathrm{H}-6^{\prime}$ and $\mathrm{H}-\alpha, \mathrm{H}-\beta$ and $\mathrm{H}-\delta, \mathrm{H}-\gamma$ and H-6, and H-6 and $\mathrm{H}-5$ indicated the relative configuration of $\mathbf{1}$ as shown in Figure 2. Thus, the structure of semedienone (1) was concluded as 2E,4E-1,5-bis(2,4-dihydroxyphenyl)penta-2,4dien-1-one.

Compound 2 showed the HRESIMS ion at $m / z 347.0902$ $[\mathrm{M}+\mathrm{Na}]^{+}$(calcd. for $\mathrm{C}_{19} \mathrm{H}_{16} \mathrm{O}_{5} \mathrm{Na}, 347.0895$ ). Its IR spectrum showed absorption bands for hydroxy $\left(3305 \mathrm{~cm}^{-1}\right)$ and carbonyl $\left(1650 \mathrm{~cm}^{-1}\right)$ groups. The ${ }^{1} \mathrm{H}$ and ${ }^{13} \mathrm{C}$ NMR spectra of 2 (Table 1) showed signals for two 1,2,4-trisubstituted aromatic rings, which resembled those of $\mathbf{1}$. Compound 2 showed the presence of six olefinic protons $\left(\delta_{\mathrm{H}} 7.26(\mathrm{~d}\right.$, $J=14.5 \mathrm{~Hz}, \mathrm{H}-\alpha$ ), 7.61 (dd, $J=14.5,11.5 \mathrm{~Hz}, \mathrm{H}-\beta), 6.62$ (dd, $J=13.7,11.5 \mathrm{~Hz}, \mathrm{H}-\gamma), 7.00(2 \mathrm{H}, \mathrm{m}, \mathrm{H}-\delta$ and $\mathrm{H}-\varepsilon)$, and 7.13 $(\mathrm{d}, J=14.6 \mathrm{~Hz}, \mathrm{H}-\zeta))$ in the ${ }^{1} \mathrm{H}$ NMR spectrum, and six olefinic carbons $\left(\delta_{\mathrm{C}} 122.8(\mathrm{C}-\alpha), 145.8(\mathrm{C}-\beta), 129.4(\mathrm{C}-\gamma)\right.$, $145.8(\mathrm{C}-\delta), 126.1(\mathrm{C}-\varepsilon), 134.3(\mathrm{C}-\zeta))$ in the ${ }^{13} \mathrm{C} \mathrm{NMR}$ spectrum. These were characteristic of those reported for (2E,4E,6E)-1,7-diarylhepta-2,4,6-trien-1-one [12]. The locations of four hydroxy groups were assigned at C-2', C- $4^{\prime}$, $\mathrm{C}-2$, and C- 4 by the observed HMBC correlations (Figure 1). Moreover, the HMBC correlations from $\mathrm{H}-6^{\prime}, \mathrm{H}-\alpha$, and $\mathrm{H}-\beta$ to $\mathrm{C}=\mathrm{O}$, from $\mathrm{H}-\alpha$ to $\mathrm{C}-\gamma$, from $\mathrm{H}-\gamma$ to $\mathrm{C}-\beta$, from $\mathrm{H}-\delta$ to $\mathrm{C}-\zeta$, from $\mathrm{H}-\varepsilon$ to $\mathrm{C}-\zeta$ and $\mathrm{C}-1$, and from $\mathrm{H}-\zeta$ to $\mathrm{C}-\delta$ and $\mathrm{C}-\varepsilon$ suggested the presence of the $\alpha, \beta, \gamma, \delta, \varepsilon, \zeta$-unsaturated carbonyl moiety in 2 . The relative configuration of $\mathbf{2}$ was deduced based on the NOESY correlations between $\mathrm{H}-5^{\prime}$ and H- $6^{\prime}, \mathrm{H}-6^{\prime}$ and $\mathrm{H}-\alpha, \mathrm{H}-\alpha$ and $\mathrm{H}-\gamma, \mathrm{H}-\beta$ and $\mathrm{H}-\delta, \mathrm{H}-\gamma$ and 
<smiles>O=C(/C=C/C=C/c1ccc(O)cc1O)c1ccc(O)cc1O</smiles>

1<smiles>O=C(/C=C/C=C/C=C/c1ccc(O)cc1O)c1ccc(O)cc1O</smiles>

2

\begin{tabular}{ccc} 
& $\mathrm{R}^{1}$ & $\mathrm{R}^{2}$ \\
\cline { 2 - 3 } $\mathbf{4}$ & $\mathrm{H}$ & $\mathrm{OH}$ \\
$\mathbf{5}$ & $\mathrm{H}$ & $\mathrm{OCH}_{3}$ \\
$\mathbf{6}$ & $\mathrm{OH}$ & $\mathrm{CH}_{3}$ \\
$\mathbf{7}$ & $\mathrm{OCH}_{3}$ & $\mathrm{OH}$
\end{tabular}

Figure 1: Structures of compounds 1-8.

$\mathrm{H}-\varepsilon, \mathrm{H}-\varepsilon$ and H-6, and H-6 and H-5 (Figure 2). Thus, the structure of semetrienone (2) was established as $2 E, 4 E, 6 E-$ 1,7-bis(2,4-dihydroxyphenyl)hepta-2,4,6-trien-1-one.

\subsection{Tyrosinase Inhibitory Activity of Isolated Compounds} from S. caudata. Compounds (1-7) were tested for their tyrosinase inhibitory activity [13]. Kojic acid, a purported skin-lightening agent, was used as a positive control. $2,4,2^{\prime}, 4^{\prime}$-Tetrahydroxychalcone (8), which was synthesized following our previous procedure [14], showed potent activity with an $\mathrm{IC}_{50}$ value of $0.016 \mu \mathrm{M}$ (Table 2). Semedienone (1) and semetrienone (2) exhibited remarkable inhibitory effect with the $\mathrm{IC}_{50}$ values of 0.033 and $0.11 \mu \mathrm{M}$, respectively, more potent than that of kojic acid $\left(\mathrm{IC}_{50}, 44.6 \mu \mathrm{M}\right)$. Additionally, compounds $\mathbf{4}$ and $\mathbf{6}$ were found to possess tyrosinase inhibitory activity with the $\mathrm{IC}_{50}$ values of 2.35 and $27.0 \mu \mathrm{M}$, respectively.

The presence of $\alpha, \beta$-unsaturated hydroxycarbonyl groups in cinnamic acid derivatives were found to enhance activity $(2 \gg 3)$. Additionally, the occurrence of a C-3 methoxy group decreased the inhibitory activity $(2 \gg 5)$ $[15,16]$. Diarylalkanoids with 2,4-disubstituted resorcinol subunit on ring $\mathrm{B}$ contributed the most to inhibitory activity [17]. Moreover, the length of the conjugated carbon chain in diarylalkanoids led to a change of activity $(8>1>2)$. This result reaffirmed the (Z)- $\beta$-phenyl- $\alpha, \beta$-unsaturated carbonyl scaffold plays an important role for tyrosinase inhibition $[18,19]$. In previous reports, diarylpentanoids such as diarylpentadiene-3-one were not significantly inhibiting tyrosinase activity [20], but some analogues showed moderate antimelanogenesis activity [21]. Some cyclic diarylheptanoids were found to have melanogenesis-inhibitory activity [22]. In this regard, semedienone (1) and semetrienone (2) could be the potent structural templates for developing new skin-lightening agents.

3.4. Docking Study of the Active Compounds 1, 2, and 8. Tyrosinase has four possible oxidation states (deoxy-, oxy-, met-, and deact-form) [23]. Met-tyrosinase, having a hydroxy and the two $\mathrm{Cu}^{2+}$ ions in the binding site, is responsible for the oxidation of catechols. In this oxidizing process, met-tyrosinase is reduced to deoxy-tyrosinase which rapidly binds dioxygen to give $o x y$-tyrosinase form. $O x y$ tyrosinase, which is the primary form of the enzyme, oxidizes both phenols and catechols to $o$-quinones by the monooxygenase and oxidase mechanisms, respectively. In the active site of $o x y$-tyrosinase, two bound $\mathrm{Cu}^{2+}$ ions and the peroxide group play a catalytic oxidation role. Mushroom tyrosinase (EC 1.14.18.1), which was used in the inhibitory assay, plays the same role with respect to $o x y$ tyrosinase form. Thus, in this study, the molecular docking studies of $\mathbf{1}, \mathbf{2}$, and $\mathbf{8}$, respectively, with $o x y$-tyrosinase (PDB ID : 1WX2) [24] were carried out to explore their interactions and inhibition mechanisms.

In molecular docking study, the imperfect scoring results (false-positive hits), which may be considered as decoys, can be occurred by predicting incorrect ligand geometries or by applying nonbinding molecules. The active and decoy ligands are similar according to some physicochemical properties (molecular weight, number of rotational bonds, total hydrogen bond donors, total hydrogen bond acceptors, topological polar surface area, and the octanol-water partition coefficient), but decoy was presumed to be inactive against a target. According to Choi et al. [25], kojic acid and hypoxanthine showed the tyrosinase inhibitory constant $\left(K_{i}\right)$ values of $13 \mu \mathrm{M}$ and $>1000 \mu \mathrm{M}$, respectively [25]. Thus, in this docking study, kojic acid and hypoxanthine was selected as the active inhibitor and the decoy molecule, respectively, to validate our docking protocol.

The docking studies were performed with Molecular Operating Environment 2016 (MOE 2016.0802) suite [26]. The top-ranked pose with the highest negative binding free energy value ( $S$ value) was selected for further interaction analysis with BIOVIA Discovery Studio Visualizer 2016 [27].

Compounds 1, 2, and $\mathbf{8}$ showed an $\mathrm{H}$-donor interaction between a hydroxy group and a peroxide bridge PER404, presenting the distances of $1.85,1.88$, and $1.78 \AA$, respectively, whereas kojic acid showed the interactions with a $\mathrm{Cu}^{2+}$ ion, HIS194, and THR203 residues (Figure 3). In the 


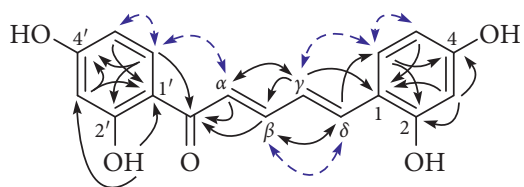

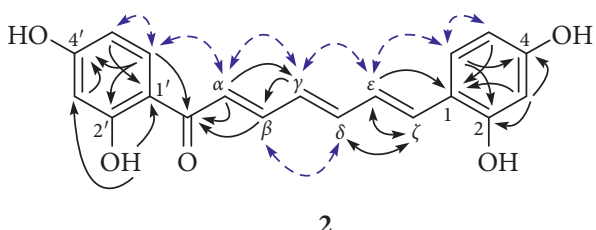

2

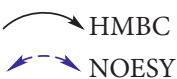

Figure 2: Significant HMBC (solid arrows) and selected NOESY correlations (blue dashed arrows) observed for 1 and 2.

TABLE 2: Tyrosinase inhibitory activities of the isolated compounds 1-8.

\begin{tabular}{lc}
\hline Compound & $\mathrm{IC}_{50}(\mu \mathrm{M})$ \\
\hline 1 & 0.033 \\
2 & 0.11 \\
3 & $>100$ \\
4 & 2.35 \\
5 & $>100$ \\
6 & 27.0 \\
7 & $>100$ \\
8 & 0.016 \\
Kojic acid $^{a}$ & 44.6 \\
\hline
\end{tabular}

${ }^{a}$ Positive control.
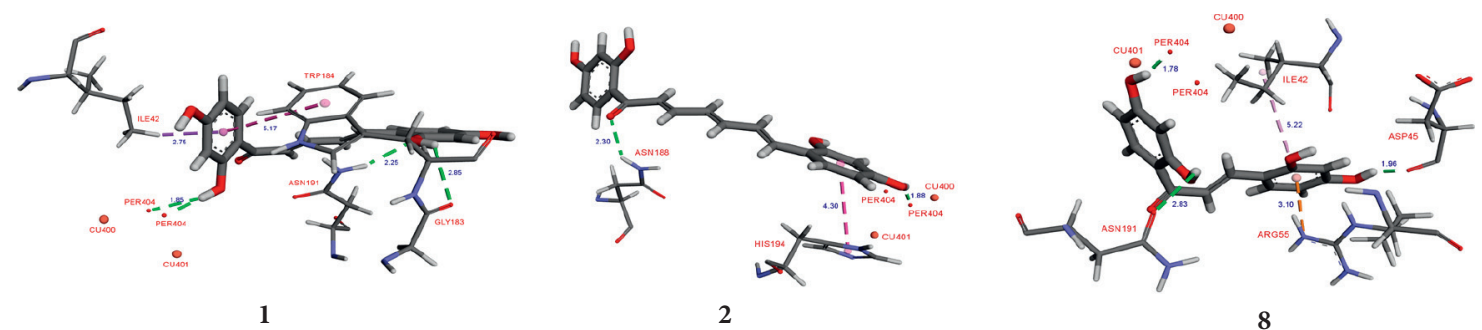

8

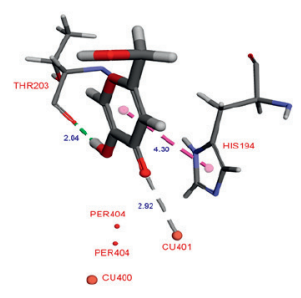

Kojic acid

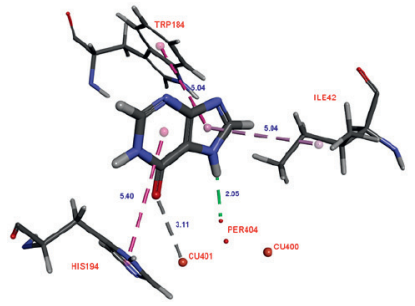

Hypoxanthine

FIgURE 3: 3D docking models of 1, 2, 8, kojic acid, and hypoxanthine with oxy-tyrosinase (1WX2).

binding pocket, compounds $\mathbf{1}$ and $\mathbf{8}$ showed more interactions with targeting residues than those of $\mathbf{2}$ (Table 3 ). These analysis results were consistent with their experimental inhibitory activities $(\mathbf{8}>\mathbf{1}>\mathbf{2})$. The C-2 hydroxy group of 1 exhibited H-bonding interactions with ASN191 and GLY183 residues. Moreover, the aromatic ring A of 1 formed $\pi-\pi$ T-shaped and $\pi-\sigma$ interactions with TRP184 and ILE42 residues, respectively. Compound 2 showed an $\mathrm{H}$-acceptor interaction between $\mathrm{C}=\mathrm{O}$ group and ASN188 residue. In addition, the aromatic ring $\mathrm{B}$ of $\mathbf{2}$ interacted with HIS194 residue via a $\pi-\pi$ stacking interaction. Thus, the $S$ values and these interactions suggested that $\mathbf{1}$ and $\mathbf{2}$ showed high binding affinity for $o x y$-tyrosinase than those of kojic acid. Hypoxanthine showed the lower negative $S$ value and the longer-distance interactions than that of kojic acid. Apparently, these results could be used to validate the abovementioned docking procedure in this study.

3.5. Proposed Biosynthetic Pathways of 1 and 2. We have proposed plausible biogenetic pathways for two new diarylalkanoids (1 and 2) (Figure 4) via the shikimate and 
TABLE 3: Docking results of $\mathbf{1}, \mathbf{2}, \mathbf{8}$, kojic acid, and hypoxanthine with oxy-tyrosinase.

\begin{tabular}{|c|c|c|c|c|}
\hline \multirow{2}{*}{ Compound } & \multicolumn{4}{|c|}{ oxy-tyrosinase (1WX2) } \\
\hline & $S$ values & Interactions & Targeting residues & Distance $(\AA)$ \\
\hline \multirow{5}{*}{1} & -5.75 & H-donor & PER404 & 1.85 \\
\hline & & & ASN191 & 2.25 \\
\hline & & & GLY183 & 2.85 \\
\hline & & $\pi-\sigma$ & ILE42 & 2.75 \\
\hline & & $\pi-\pi$ & TRP184 & 5.17 \\
\hline \multirow{3}{*}{2} & -6.37 & H-donor & PER404 & 1.88 \\
\hline & & $\mathrm{H}$-acceptor & ASN188 & 2.30 \\
\hline & & $\pi-\pi$ & HIS194 & 4.30 \\
\hline \multirow{5}{*}{8} & -5.54 & H-donor & PER404 & 1.78 \\
\hline & & & ASP45 & 1.96 \\
\hline & & & ASN191 & 2.83 \\
\hline & & $\pi$-alkyl & ILE42 & 5.22 \\
\hline & & $\pi$-cation & ARG55 & 3.10 \\
\hline \multirow{3}{*}{ Kojic acid ${ }^{a}$} & -4.50 & H-donor & THR203 & 2.04 \\
\hline & & Metal-acceptor & CU401 & 2.92 \\
\hline & & $\pi-\pi$ & HIS194 & 4.30 \\
\hline \multirow{5}{*}{ Hypoxanthine $^{b}$} & -4.34 & H-donor & PER404 & 2.05 \\
\hline & & Metal-acceptor & CU401 & 3.11 \\
\hline & & $\pi-\pi$ & HIS194 & 5.40 \\
\hline & & & TRP184 & 5.04 \\
\hline & & $\pi$-alkyl & ILE42 & 5.04 \\
\hline
\end{tabular}

${ }^{a}$ Positive control. ${ }^{b}$ Decoy molecule.

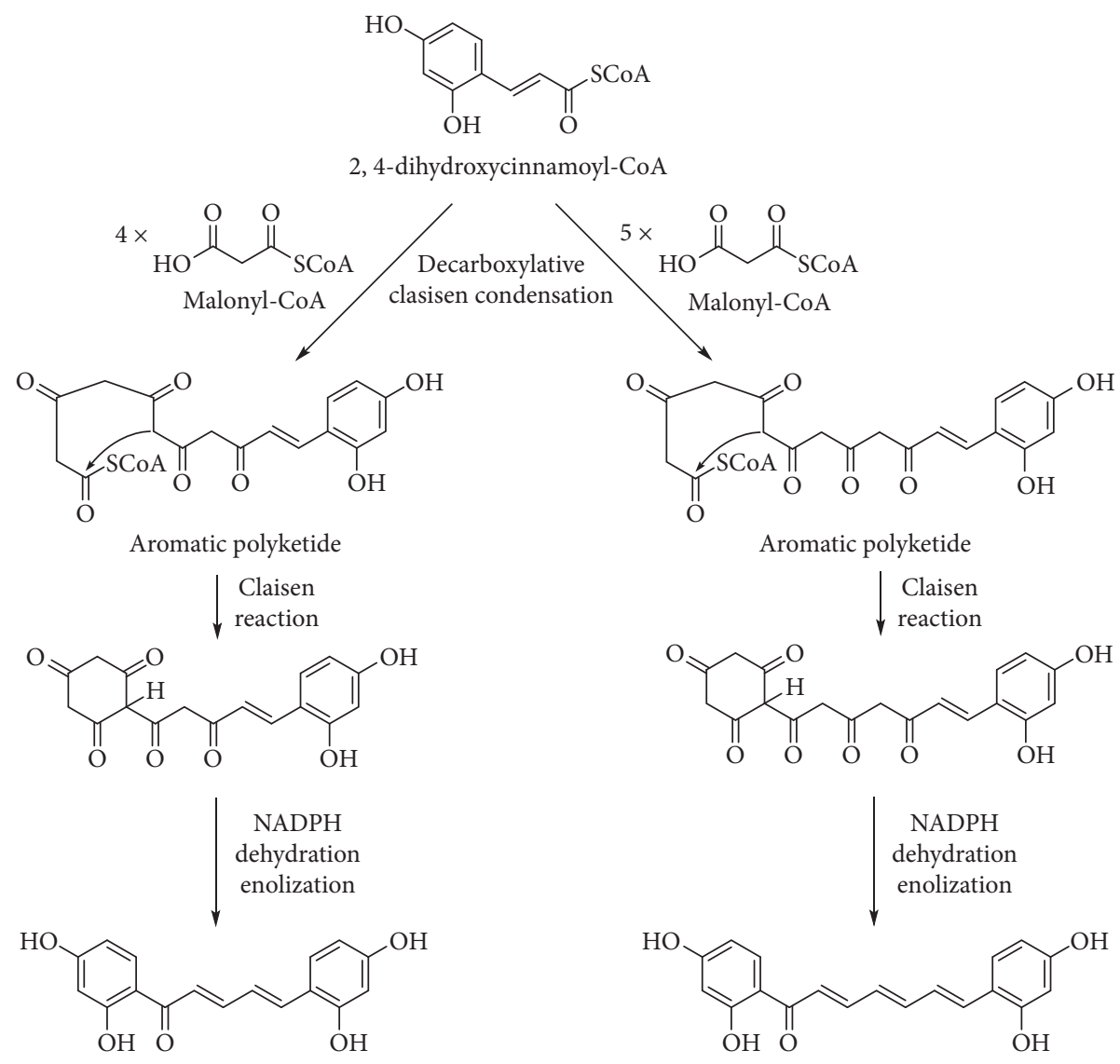

FIGURE 4: Plausible biosynthetic pathways for diarylalkanoids $\mathbf{1}$ and 2. 
acetate pathways [28]. $\alpha$-Ketoglutarate-dependent hydroxylase is responsible for the C-2 hydroxylation of $p$-coumaroyl-CoA to give 2,4-dihydroxycinnamoyl-CoA [29]. It is condensed with four or five malonyl-CoA moieties to afford the corresponding polyketides, which undergo the intramolecular ring closure via Claisen reaction. After that, reduction, dehydration, and enolization must occur to give rise to 1 and 2 .

\section{Conclusions}

From the $\mathrm{CHCl}_{3}$-soluble extract of the stems of S. caudata, two new diarylalkanoids were isolated together with five known compounds. Compounds $\mathbf{1}$ and $\mathbf{2}$ were found to possess potent tyrosinase inhibitory activity with the $\mathrm{IC}_{50}$ values of 0.033 and $0.11 \mu \mathrm{M}$, respectively. Binding interaction analyses between the $o x y$-tyrosinase active site and the active compounds ( $\mathbf{1}$ and $\mathbf{2}$ ) have been performed. Plausible biogenetic pathways for formation of two new diarylalkanoids (1 and 2) were also proposed.

\section{Data Availability}

The data used to support the findings of this study are included within the article.

\section{Conflicts of Interest}

The authors declare that there are no conflicts of interest regarding the publication of this paper.

\section{Acknowledgments}

This research was funded by Vietnam National University Ho Chi Minh City (VNU-HCM) under grant no. NCM2020$18-01$.

\section{Supplementary Materials}

${ }^{1} \mathrm{H}$ and ${ }^{13} \mathrm{C}$ NMR spectra of two new compounds, semedienone (1) and semetrienone (2). (Supplementary Materials)

\section{References}

[1] J. N. Rodríguez-López, J. Tudela, R. Varón, F. García-Carmona, and F. García-Cánovas, "Analysis of a kinetic model for melanin biosynthesis pathway," Journal of Biological Chemistry, vol. 267, no. 6, pp. 3801-3810, 1992.

[2] H. Decker and F. Tuczek, "Tyrosinase/catecholoxidase activity of hemocyanins: structural basis and molecular mechanism," Trends in Biochemical Sciences, vol. 25, no. 8, pp. 392-397, 2000.

[3] T. Pillaiyar, M. Manickam, and V. Namasivayam, "Skin whitening agents: medicinal chemistry perspective of tyrosinase inhibitors," Journal of Enzyme Inhibition and Medicinal Chemistry, vol. 32, no. 1, pp. 403-425, 2017.

[4] P. H. Dang, T. T. Nguyen, T. H. Le, H. X. Nguyen, M. T. T. Nguyen, and N. T. Nguyen, "A new bischromanone from the stems of Semecarpus caudata," Natural Product Research, vol. 32, no. 15, pp. 1745-1750, 2018.
[5] V. Ibrahim, N. Volkova, S.-H. Pyo, G. Mamo, and R. HattiKaul, "Laccase catalysed modification of lignin subunits and coupling to p-aminobenzoic acid," Journal of Molecular Catalysis B: Enzymatic, vol. 97, pp. 45-53, 2013.

[6] J. Sun, X.-M. He, M.-M. Zhao, L. Li, C.-B. Li, and Y. Dong, "Antioxidant and nitrite-scavenging capacities of phenolic compounds from sugarcane (Saccharum officinarum L.) tops," Molecules, vol. 19, no. 9, pp. 13147-13160, 2014.

[7] F. Carta, D. Vullo, A. Maresca, A. Scozzafava, and C. T. Supuran, "Mono-/dihydroxybenzoic acid esters and phenol pyridinium derivatives as inhibitors of the mammalian carbonic anhydrase isoforms I, II, VII, IX, XII and XIV," Bioorganic \& Medicinal Chemistry, vol. 21, no. 6, pp. 15641569, 2013.

[8] A. Baranovsky, B. Schmitt, D. J. Fowler, and B. Schneider, "Synthesis of new biosynthetically important diarylheptanoids and their oxa- and fluoro-analogues by three different strategies," Synthetic Communications, vol. 33, no. 6, pp. 1019-1045, 2003.

[9] H. Xiao and K. Parkin, "Isolation and identification of phase II enzyme-inducing agents from nonpolar extracts of green onion (alliumspp.)," Journal of Agricultural and Food Chemistry, vol. 54, no. 22, pp. 8417-8424, 2006.

[10] N. Desideri, R. Fioravanti, L. Proietti Monaco et al., "1,5Diphenylpenta-2,4-dien-1-ones as potent and selective monoamine oxidase-B inhibitors," European Journal of $\mathrm{Me}$ dicinal Chemistry, vol. 59, pp. 91-100, 2013.

[11] S. M. Mohd Faudzi, S. W. Leong, F. Abas et al., "Synthesis, biological evaluation and QSAR studies of diarylpentanoid analogues as potential nitric oxide inhibitors," Medicinal Chemistry Communication, vol. 6, no. 6, pp. 1069-1080, 2015.

[12] H. Mohamad, N. H. Lajis, F. Abas et al., "Antioxidative constituents ofEtlingeraelatior," Journal of Natural Products, vol. 68, no. 2, pp. 285-288, 2005.

[13] E. T. Arung, I. W. Kusuma, Y. M. Iskandar, S. Yasutake, K. Shimizu, and R. Kondo, "Screening of Indonesian plants for tyrosinase inhibitory activity," Journal of Wood Science, vol. 51, no. 5, pp. 520-525, 2005.

[14] T. H. Bui, N. T. Nguyen, P. H. Dang, H. X. Nguyen, and M. T. T. Nguyen, "Design and synthesis of chalcone derivatives as potential non-purine xanthine oxidase inhibitors," Springerplus, vol. 5, no. 1, pp. 1789-1796, 2016.

[15] T. Takahashi and M. Miyazawa, "Tyrosinase inhibitory activities of cinnamic acid analogues," Die Pharmazie-An International Journal of Pharmaceutical Sciences, vol. 65, no. 12, pp. 913-918, 2010.

[16] Z. Zhang, J. Liu, F. Wu, and L. Zhao, "Inhibitory effects of substituted cinnamic acid esters on mushroom tyrosinase," Letters in Drug Design \& Discovery, vol. 10, no. 6, pp. 529-534, 2013.

[17] S. Khatib, O. Nerya, R. Musa, M. Shmuel, S. Tamir, and J. Vaya, "Chalcones as potent tyrosinase inhibitors: the importance of a 2,4-substituted resorcinol moiety," Bioorganic \& Medicinal Chemistry, vol. 13, no. 2, pp. 433-441, 2005.

[18] H. R. Kim, H. J. Lee, Y. J. Choi et al., "Benzylidene-linked thiohydantoin derivatives as inhibitors of tyrosinase and melanogenesis: importance of the $\beta$-phenyl- $\alpha, \beta$-unsaturated carbonyl functionality," Medicinal Chemistry Communication, vol. 5, no. 9, pp. 1410-1417, 2014.

[19] S. J. Kim, J. Yang, S. Lee et al., "The tyrosinase inhibitory effects of isoxazolone derivatives with a (Z)- $\beta$-phenyl- $\alpha$, $\beta$-unsaturated carbonyl scaffold," Bioorganic \& Medicinal Chemistry, vol. 26, no. 14, pp. 3882-3889, 2018. 
[20] K.-H. Lee, F. H. Ab Aziz, A. Syahida et al., "Synthesis and biological evaluation of curcumin-like diarylpentanoid analogues for anti-inflammatory, antioxidant and anti-tyrosinase activities," European Journal of Medicinal Chemistry, vol. 44, no. 8, pp. 3195-3200, 2009.

[21] T. Hosoya, A. Nakata, F. Yamasaki et al., "Curcumin-like diarylpentanoid analogues as melanogenesis inhibitors," Journal of Natural Medicines, vol. 66, no. 1, pp. 166-176, 2012.

[22] T. Akihisa, A. Takeda, H. Akazawa et al., "Melanogenesisinhibitory and cytotoxic activities of diarylheptanoids from Acer nikoense bark and their derivatives," Chemistry \& Biodiversity, vol. 9, no. 8, pp. 1475-1489, 2012.

[23] C. A. Ramsden and P. A. Riley, "Tyrosinase: the four oxidation states of the active site and their relevance to enzymatic activation, oxidation and inactivation," Bioorganic \& Medicinal Chemistry, vol. 22, no. 8, pp. 2388-2395, 2014.

[24] Y. Matoba, T. Kumagai, A. Yamamoto, H. Yoshitsu, and M. Sugiyama, "Crystallographic evidence that the dinuclear copper center of tyrosinase is flexible during catalysis," Journal of Biological Chemistry, vol. 281, no. 13, pp. 89818990, 2006.

[25] J. Choi, Y. M. Lee, and J. G. Jee, "Thiopurine drugs repositioned as tyrosinase inhibitors," International Journal of Molecular Sciences, vol. 19, no. 1, p. 77, 2018.

[26] Chemical Computing Group, "Molecular operating environment (MOE) 2016," Chemical Computing Group, Montreal, QC, Canada, 2016.

[27] Dassault Systèmes BIOVIA, BIOVIA Discovery Studio Visualizer, Dassault Systèmes BIOVIA, San Diego, CA, USA, 2016.

[28] P. M. Dewick, Medicinal Natural Products: A Biosynthetic Approach, John Wiley \& Sons, Hoboken, NJ, USA, 3rd edition, 2009.

[29] S. Martinez and R. P. Hausinger, "Catalytic mechanisms of $\mathrm{Fe}(\mathrm{II})$ - and 2-oxoglutarate-dependent oxygenases," Journal of Biological Chemistry, vol. 290, no. 34, pp. 20702-20711, 2015. 